African Journal of Educational Studies in Mathematics and Sciences Vol. 15, No. 2., 2019

\title{
Students' conceptual understanding of electricity and magnetism and its implications: A review
}

\author{
A. ${ }^{1}$ Mbonyiryivuze, L. L. ${ }^{2}$ Yadav, \& M. M. ${ }^{3}$ Amadalo
}

\begin{abstract}
Physics subject continues to be considered as difficult and unattractive by students. This leads to the development of negative attitudes towards the subject. Electricity and magnetism as one of the most important areas in physics is particularly considered as difficult due to their abstract nature. Different studies on students' conceptual understanding of electricity and magnetism have been conducted and several instructional strategies for conceptual change in this subject matter have been provided. However, there are still some persisting misconceptions even after being treated by those suggested instructional strategies. By using diagnostic tests and remedial approaches to sort out learning barriers, there is a possibility that students' performance might improve, which would likely lead to disappearing these learning barriers and retaining the appropriate concepts over time scales beyond the assessment schedule of individual classes. Therefore, after reporting on the impact of students' preconceptions on learning, this review paper also highlights some existing studies on students' misconceptions in electricity and magnetism. The paper also updates physics educators and researchers on some conceptual tests and assessments used to test students' misconceptions in electricity and magnetism and some suggested strategies for remedying those misconceptions. Some educational implications and practical recommendations for effective teaching and learning in electricity and magnetism are also outlined.
\end{abstract}

Keywords: $\quad$ students' conceptual understanding; electricity; magnetism; preconceptions; misconceptions; conceptual tests

\section{Introduction}

Success in quantitative problem solving is not a reliable measure of conceptual understanding (McDermott \& Shaffer, 1992; Mazur, 1997). Research has reported that even if students perform well in quantitative problem solving, they struggle with conceptual questions (McDermott \& Shaffer, 1992; Shaffer \& McDermott, 1992; Mazur, 1997; Wieman \& Perkins, 2005; Muise, 2015; Von Korff, et al., 2016). Some students obtain high scores while lacking a deep understanding of some basic concepts in physics topics (McDermott \& Shaffer, 1992; Elby, 1999; Hussain, Latiff, $\&$ Yahaya, 2012). It has also been reported that in many developing countries, a big number of students do not develop the necessary conceptual understanding when asked to solve problems.

${ }^{1}$ Agnes Mbonyiryivuze is a PhD student in Physics Education at the African Centre of Excellence for Innovative Teaching and Learning Mathematics and Science (ACEITLMS), University of Rwanda- College of Education (URCE), Rukara Campus, Rwanda. Email: mbonyiryivuzeagnes@yahoo.com, +250785820176

${ }^{2}$ Lakhan Lal Yadav is the Director, ACEITLMS, University of Rwanda- College of Education, Rukara Campus, Rwanda. Email: yadavll@yahoo.com

${ }^{3}$ Maurice Musasia Amadalo is an Associate Professor of Physics Education at Kaimosi Friends University College, Kaimosi, Kenya. Email: mmamadalo@yahoo.com

Open Access article distributed under the terms of the Creative Commons Attributions License [CC BY-NC-ND 4.0] http://creativecommons.org/licenses/by-nc-nd/4.0. DOI: https://dx.doi.org/10.4314/ajesms.v15i2.5 
These students try only to memorize mathematical formulas (Elby, 1999; Uwizeyimana, Yadav, Musengimana, \& Uwamahoro, 2018). Actually, learning is not simply the acquisition of a set of correct responses. It is rather a process of conceptual formation and change (Posner, Strike, Hewson, \& Gertzog, 1982). Therefore, students with both good physics conceptual understanding and problem-solving skills will be able to relate the important information to what they already know without just memorizing it the way it is presented (Mazur, 1997; NRC, 1997). Therefore, students need to be assisted in developing their physics conceptual understanding allowing them to link physics with the real world and then developing their problem-solving skills (Hake, 1998).

\section{Influence of Teaching Methods on Students' Conceptual Understanding}

One of the reasons for this difference may be due to how physics classes are taught using traditional methods. In a traditional class, the subject matter is nearly always delivered in monologue fashion in front of a passive audience (Mazur, 1997; Maloney, O'Kuma, Hieggelke, \& Van, 2001; Muise, 2015; Uwizeyimana, Yadav, Musengimana, \& Uwamahoro, 2018). While using traditional teaching strategy, it is not easy to provide adequate opportunities for students to critically think in the course of developed arguments. Problem-solving is reinforced by lectures as the most important way to master the material. Actually, only exceptional lectures can maintain students' attention for the entire traditional-based lecture session due to the way materials are presented (Muise, 2015). Besides, traditional teaching strategies which are usually teachercentered have been claimed to be ineffective in developing students' conceptual understanding (Hake, 1998); (Crouch \& Mazur, 2001; Von Korff, et al., 2016; Amadalo, Ocholla, \& Sakwa, 2016). Some studies reported that noticeable conceptual understanding change in learners after being taught using traditional teaching methods was short-lived. Instead of being challenged by what has been learned during teaching periods, learners construct observations supporting their pre-teaching understanding (Mulhall, Brian, \& Gunstone, 2001). As students are active constructors of their-knowledge (Arnold \& Millar, 1987), student-centered teaching strategies help students constructing knowledge on their own and enhance their conceptual understanding with an educator as facilitator.

\section{Why Electricity and Magnetism?}

Electricity and magnetism is considered as a central area of physics and science curricula at primary, secondary as well as tertiary levels of education (Gunstone, Mulhall, \& McKittrick, 2009). There are more opportunities for practical investigations offered by electricity and magnetism including that for knowledge demonstration and understanding through both talk and activity for children (Glauert, 2009). Additionally, electricity and magnetism as one of the basic areas and important topics in physics have applications encompassing many aspects of our everyday life. However, this area has been reported to have several concepts in which students develop views that are different from those accepted scientifically (Turgut, Gürbüz, \& Turgut, 2011; Li, 2012). Electricity and magnetism related concepts are particularly problematic due to their abstract and complex nature making their understanding difficult for students (Arnold \& Millar, 1987; Mulhall, Brian, \& Gunstone, 2001; Mioković, Ganzberger, \& Radolić, 2012). Moreover, in the study conducted about tutors' perceptions about science curriculum reforms and challenges for their implementation in Teacher Training Colleges in Rwanda, it was found that most science tutors experienced difficulties to teach these topics (Kanamugire, Yadav, \& Mbonyiryivuze, 2019). Therefore, in addition to the impact of students' preconceptions on learning and the importance of considering students' preconceptions for effective learning, this review paper highlights some existing studies on students' misconceptions in electricity and magnetism. Moreover, the paper updates physics educators and researchers on some suggested strategies for remedying misconceptions. Some educational implications and practical 
recommendations for effective teaching and learning in electricity and magnetism are also outlined.

\section{The Impact of Students' Preconceptions on Learning}

Studies of physics students' conceptual understanding and their misconceptions have become a central issue in physics due to their effect to students learning from the past four decades (Halloun \& Hestenes, 1985; Goldberg \& McDermott, 1987; Maloney, O’Kuma, Hieggelke, \& Heuvelen, 2001; Coletta \& Philips, 2005; Lark, 2007; Aydeniz, 2010; Alwan, 2011; Christensen, Meltzer, \& Nguyen, 2011; Mashood \& Singh, 2012; Rathore, 2016; McColgan, Finn, Broder, \& Hassel, 2017). While entering physics class, students have already a number of ideas and preconceptions on how the physical systems behave (Arnold \& Millar, 1987; Maloney, O'Kuma, Hieggelke, \& Van, 2001; Philippi, 2010; Turgut, Gürbüz, \& Turgut, 2011; Li, 2012), Mbonyiryivuze, Kanamugire, Yadav, \& Ntivuguruzwa, 2018). Students' preconceptions and ideas are formed during their interactions within physical and social environment as well as informal experience and language (Arnold \& Millar, 1987; Küçüközer \& Kocakülah, 2007; Turgut, Gürbüz, \& Turgut, 2011; Li, 2012). Usually, those preconceptions are inconsistent with scientifically accepted principles and concepts of science (Turgut, Gürbüz, \& Turgut, 2011; Mbonyiryivuze, Kanamugire, Yadav, \& Ntivuguruzwa, 2018). Therefore, much interest has been attracted to study students' prior knowledge of science and the relationship between students' prior knowledge and scientifically accepted principles. That is why much of the good science curricula attempt to bridge the gap between the imperfect knowledge of learners and the scientifically accepted principles (Wallace \& Louden, 1998; Mbonyiryivuze, Kanamugire, Yadav, \& Ntivuguruzwa, 2018).

Students' preconceptions and ideas may interfere with learning during and after the learning process (Küçüközer \& Kocakülah, 2007; Sukariasih, 2016) and influence students' receptivity of new ideas (Arnold \& Millar, 1987). When preconceptions are correct, these can be used as building blocks for conceptual understanding. But when these are wrong and persistent, they become obstacles for effective learning (Afra, Osta, \& Zoubeir, 2009). In this paper, misconceptions refer to preconceptions that are inconsistent with experts or accepted scientific views as used in literature (Küçüközer \& Kocakülah, 2007). Besides to be robust and difficult to change without a proper intervention (Posner, Strike, Hewson, \& Gertzog, 1982; NRC, 1997; Li, 2012), misconceptions are often incomplete and inconsistent (Philippi, 2010). Research findings consistently show that misconceptions are deeply held and they are likely to remain in the students' cognitive structure after instruction, or even to reemerge some weeks after students have displayed some initial understanding immediately following instruction (Clement, 1982; Halloun \& Hestenes, 1985; Cakir, 2008). Over the past three decades, studies of students' misconceptions have become a central issue in physics due to their effect to students' learning (Clement, 1982; Halloun \& Hestenes, 1985; Goldberg \& McDermott, 1987; Christensen, Meltzer, \& Nguyen, 2011; Turgut, Gürbüz, \& Turgut, 2011). Different misconceptions reported in literature were common among students from different countries, different backgrounds, and different educational levels and systems (McDermott \& Shaffer, 1992; Afra, Osta, \& Zoubeir, 2009). Some studies also show that there are differences associated with gender in terms some misconceptions held by students and their performance. Males outperformed females and tended to use fewer misconceptions comparing to their counterparts (Engelhardt \& Beichner, 2004), but it is debatable. Moreover, misconceptions were reported to be held by pre-service and in-service physics teachers (Afra, Osta, \& Zoubeir, 2009; Gunstone, Mulhall, \& McKittrick, 2009). 
Students' conceptual understanding of electricity and magnetism and its implications: A review

A. Mbonyiryivuze, L. L. Yadav, \& M. M. Amadalo

\section{Some Studies on Students' Conceptual Understanding in Electricity and Magnetism}

Several researches show that students have misconceptions and many common difficulties in understanding concepts related to electricity and magnetism topics (McDermott \& Shaffer, 1992; Shaffer \& McDermott, 1992; Maloney, O’Kuma, Hieggelke, \& Heuvelen, 2001; Küçüközer \& Kocakülah, 2007; Afra, Osta, \& Zoubeir, 2009; Pollock, 2009; Glauert, 2009; Hussain, Latiff, \& Yahaya, 2012; Li, 2012; McColgan, Finn, Broder, \& Hassel, 2017; Li \& Singh, 2017). Most of the reported studies have been conducted on students while few involved physics teachers ( (Mulhall, Brian, \& Gunstone, 2001; Gunstone, Mulhall, \& McKittrick, 2009; Van der Merwe \& Gaigher, 2011).

While conducting their research using conceptual understanding tests and semi-structured interviews, Küçüközer and Kocakülah (2007) identified some additional misconceptions to already identified students' misconceptions about simple electric circuits through literature. Those new identified students' misconceptions are the idea that "no bulb lights if the switch is off" and "bulbs connected in parallel give better light than those connected in series". It was argued that the found misconceptions were most likely due to students' everyday languages and prior teaching as highlighted in the literature (Küçüközer \& Kocakülah, 2007). Likewise, Turgut, et al. (2011) found that a considerable number of students have misconceptions about electric current concept. Students could not distinguish between some concepts such as potential difference, current, power, and energy because they were using them interchangeably (Turgut, Gürbüz, \& Turgut, 2011). Authors argue that most of these misconceptions are originated from students' experiences of daily life. Moreover, the reported potential sources of misunderstandings were instructional practices, textbooks and excessive reliance on daily language (Turgut, Gürbüz, \& Turgut, 2011). In 2009, Glauert conducted a qualitative study on twenty-eight children aged five and six by using interviews and field notes to investigate how young children understand electric circuits. These children were shown different circuits and asked to predict whether those circuits would work and explain why (Glauert, 2009). Even if the relationship between practical competences, predictions and explanations was found to be not straight forward for these children, the range of responses showed similarities to those of older students reported in previous researches (Glauert, 2009). Afra et al. (2009) found that most of the alternative conceptions reported in literature were found amongst the participants from their study on 12 students of grade nine of Lebanese track class at one American high school. The study conducted by Husain, Latiff, \& Yahaya (2012) on first-year electrical engineering students using concept tests and interviews revealed that students relied heavily on Ohm's law. In fact, students considered the current to be a prime concept. Students believed that when there is no current, there is also no voltage and therefore no resistance (Hussain, Latiff, \& Yahaya, 2012).

Both teachers and students have been reported to hold some misconceptions that are hard to give up especially when they had such belief for long time. The study conducted by Gunstone et al. (2009) on eight senior secondary school physics teachers and three authors of physics textbooks that were in use during the period of investigation revealed a wide range of perceptions among physics teachers about difficulties of both the concepts of direct current (DC) electricity and the instructional methods used to teach the subject matter (Gunstone, Mulhall, \& McKittrick, 2009). For some teachers and one author, the levels of conceptual understanding of the concepts of DC electricity were of particular concern. The connection between the extent to which interviewed physics teachers understood concepts of DC electricity themselves, their perceptions of learning electricity, and difficulties of teaching electricity was found to be weak. Some teachers considering this area easy to teach tended to have simple views of learning and understanding of concepts of DC electricity, while those with more informed views of learning tended to have a 
better understanding of the concepts of DC electricity and to a good judgment on difficulties of teaching this area (Gunstone, Mulhall, \& McKittrick, 2009). The authors claimed that the found inadequacies among teachers would most likely to be associated with inadequacies in the contents and quality of undergraduate physics teaching. It was found that some undergraduate physics programs focus more on complex mathematical representations and solutions of more complex problems while little or no attention is paid to concepts such as voltage, potential difference, and electromotive force (Gunstone, Mulhall, \& McKittrick, 2009). Even if the reflection on the nature of complex and abstract physics concepts is expected for undergraduate study, two physics teachers showed clearly that the experience of being interviewed lead them to reflect on the nature of some concepts of DC electricity for the first time. Therefore, the expectation of reflection on the nature of complex and abstract physics concepts was not met by either of these physics teachers (Gunstone, Mulhall, \& McKittrick, 2009). Studies revealed that some of the students' misconceptions and difficulties are not adequately addressed by traditional teaching methods (McDermott \& Shaffer, 1992). So, further work on teaching and learning activities helping in rectifying students' misconceptions are needed (Hussain, Latiff, \& Yahaya, 2012).

\section{Identification of Students' Misconception in Electricity and Magnetism}

One of the aims of physics education research is to determine how to assist students in their understanding of the discipline. This includes determining what difficulties and misconceptions students have with physics concepts, why they have these difficulties and misconceptions, and how to address these difficulties and misconceptions (Turgut, Gürbüz, \& Turgut, 2011; Moodley $\&$ Gaigher, 2019). The assessment of the student's learning is of critical importance in terms of revealing effective pedagogical learning tools and strategies. Formative assessments designed to enhance teaching and learning help teachers and students to seek information about the state of the student's learning and then use the acquired information to adapt teaching and learning to meet the student's needs (Dufresne \& Gerace, 2004). Formative assessments should be frequently arranged during instruction in various forms to monitor learning progress as highlighted in the literature (Yadav, 2005). In fact, by using validated physics surveys on various topics, one can probe the extent to which students master those concepts after traditional instruction and for assessing innovative curricula and pedagogies (Li \& Singh, 2017). A number of assessment tools currently exist in physics education. Those assessment tools that have been designed cover different physics domains including force ( (Hestenes, Wells, \& Swackhamer, 1992), direct current (Engelhardt \& Beichner, 2004), electricity and magnetism (Maloney, O'Kuma, Hieggelke, \& Heuvelen, 2001; Ding, Chabay, Sherwood, \& Beichner, 2006; Turgut, Gürbüz, \& Turgut, 2011).-This section provides some conceptual tests and assessments designed to test students' misconceptions in electricity and magnetism.

The Conceptual Survey of Electricity and Magnetism (CSEM) is one of the broad survey instruments designed in 2001 by Maloney et al. to assess students' knowledge about electricity and magnetism. This survey consists of a 32-question, multiple-choice test (Maloney, O'Kuma, Hieggelke, \& Heuvelen, 2001). While designing CSEM, the authors were interested at designing qualitative instrument that will allow them to assess both students' initial knowledge in electricity and magnetism and the effect of various form of instruction on changing students' initial knowledge facilitating comparisons among courses and instructional methods (Maloney, O'Kuma, Hieggelke, \& Heuvelen, 2001). Engelhardt \& Beichner (2004) designed two versions of the Determining and Interpreting Resistive Electric Circuit Concepts Tests (DIRECT) to assess students' understanding of a variety of DC resistive electric circuits concepts. These tests could be useful in evaluating curriculum or instructional methods as well as providing insight into 
students' conceptual understanding of DC circuit phenomena (Engelhardt \& Beichner, 2004). The Electrical Current Conceptual Tests (ECCT) are other multiple tests that have been developed to investigate $10^{\text {th }}$-grade students' understanding of electric current (Turgut, Gürbüz, \& Turgut, 2011). Teachers have been recommended to use these tests for even formative evaluation. Even though these multiple tests cannot investigate students' answers in deep, they can be easily administered to a large number of students. Moreover, they are objective due to scoring and can be easily analyzed. Therefore, instead of using interviews, one-phase test, and two-phase tests, the researcher may prefer to use three-phase tests (Turgut, Gürbüz, \& Turgut, 2011). Moreover, in their study, Abdullah and Lim (2013) used the Parallel Circuit Conceptual Understanding Test (PCCUT) to test students' conceptual understanding of parallel resistors. Moreover, the same test was used to explore the possibility of profiling students according to their understanding. The PCCUT instrument focused on six domains including the meaning of parallel, practical knowledge of current, voltage, resistance, circuit connection as well as mental model (Abdullaha \& Limb, 2012). It was argued that PCCUT is a valid and reliable instrument to measure students' basic knowledge and identification of their difficulties in parallel resistors before they start the introductory course in electricity. The Electricity and Magnetism Conceptual Assessment (EMCA) is another test that has been designed to assess students' conceptual understanding of electricity (McColgan, Finn, Broder, \& Hassel, 2017). Li and Singh (2017) have also developed and validated a 30 item multiple-choice test on magnetism called Magnetism Conceptual Survey (MCS). This test was designed to assess introductory physics students' understanding of magnetism concepts and to explore the difficulties students have in interpreting magnetism concepts (Li \& Singh, 2017). The following section reports about some possible remedies to overcome students' misconceptions in electricity and magnetism.

\section{Remedies to Overcome Students' Misconceptions in Electricity and Magnetism}

Successful implementation of teaching strategies helping students to overcome their misconceptions requires knowledge about students' possible misconceptions and their prior knowledge (NRC, 1997; Turgut, Gürbüz, \& Turgut, 2011). Teachers need to identify students' prior knowledge and misconceptions before introducing the new concept to students. This will ease the identification of appropriate teaching strategies helping students to overcome their misconceptions (NRC, 1997; Maloney, O’Kuma, Hieggelke, \& Heuvelen, 2001; Muthiraparampil, 2012, Abdullaha \& Limb, 2012; Villarino, 2015; Uwizeyimana, Yadav, Musengimana, \& Uwamahoro, 2018). However, being aware of students' misconceptions is not enough for teachers to correct those misconceptions as they may even emerge during instruction. Therefore, good guidance will help students to avoid misinterpretation of the new concepts leading to modification of what they are taught and observed based upon prior knowledge (Li, 2012). After introducing new ideas or cultural tools where necessary and provide the support and guidance for students to make sense of these new ideas for themselves, teachers have to listen and diagnose the ways in which the instructional activities are being interpreted to inform further action (Driver, Asoko, Leach, Mortimer, \& Scott, 1994). Different instructional strategies have been used to improve students' conceptual understanding of electricity and magnetism. However, a key question that remains largely unanswered is whether instructional strategies that yield high conceptual understanding gains represent permanent impacts or if their effects are long-lived (Pollock, 2009). It has been reported that by using pre-post testing, there is a possibility that students' performance might represent some form of conceptual rote learning which would likely be disappeared over time scales much beyond the examination schedule of individual classes (Pollock, 2009). Therefore, there is great interest in research investigating the effects of instructional strategies to improve students' conceptual understanding of electricity and magnetism. 
One of the proposed remedies for students' misconceptions in electricity and magnetism is the identification and clarification of students' prior knowledge and misconceptions. This is done by using questionnaires before the introduction of electricity and magnetism lessons. This strategy allows educators to explain related concepts with correct reasoning to help students to get rid of those misconceptions. The success of this approach requires good content knowledge in the topic for educators, library and well-equipped laboratories (Muthiraparampil, 2012). In fact, by using this approach, teachers can easily guide students to gain scientifically accepted conceptions by using appropriate teaching methods helping students to overcome their misconceptions (Turgut, Gürbüz, \& Turgut, 2011).

Constructive approaches like problem-based learning (PBL) and inquiry-based approaches which are student-centered were also recommended to enhance students' knowledge of electricity and magnetism (Afra, Osta, \& Zoubeir, 2009). One reason for the broad, intuitive appeal that has driven the growth of constructivism as instructional model may be that it includes aspects of Piagetian and Vygotskian learning theories; explicitly, the importance of determining prior knowledge, or existing cognitive frameworks to drive conceptual change (Cakir, 2008). According to Cakir (2008), conceptual change can be seen in terms of recognizing, evaluating, reconstructing. In fact, the individual needs to recognize the existence and nature of their current conceptions, decides whether or not to evaluate the utility and worth of these conceptions, and whether or not to reconstruct these conceptions (Cakir, 2008). A model of conceptual change that was developed by Posner, Strike, Hewson, and Gertzog (1982) at Cornell University describes learning as a process in which a learner changes his/her conceptions by capturing new conceptions or exchanging existing conceptions for new ones (Posner, Strike, Hewson, \& Gertzog, 1982; Cakir, 2008). Research reported that there are analogous patterns of conceptual change in learning. For conceptual change model, sometimes students assimilate new concepts by using existing concepts to deal with new phenomena. However, when the students' current concepts arc inadequate to allow them to understand some new phenomenon successfully, they have to replace or reorganize their central concepts by using accommodation (Posner, Strike, Hewson, \& Gertzog, 1982; Cakir, 2008). One of different conditions of the accommodation process to take place is that there must be dissatisfaction with the existing conceptions. In fact, an individual has to hold a store of unsolved puzzles or anomalics and lost faith in the capacity of his current concepts to solve these problems. Secondly, the individual must be able to grasp how experience can be structured by a new concept sufficiently to explore the possibilities inherent in it. Moreover, any new concept adopted must at least appear to have the capacity to solve the problems generated by its predecessors. Finally, the new concept should have the potential to be extended. to open up new areas of inquiry (Posner, Strike, Hewson, \& Gertzog, 1982; Cakir, 2008).

Furthermore, other actively engaging teaching methods including concept maps (NRC, 1997; Cakir, 2008; Turgut, Gürbüz, \& Turgut, 2011), demonstrations, cooperative learning and handson activities that can address students' misconceptions have been highlighted (Turgut, Gürbüz, \& Turgut, 2011). The Interactive Engagement (IE) methods that have been introduced in order to bridge the gap between conceptual understanding and problem solving ability may also help students to overcome their misconceptions (Hake, 1998; Crouch \& Mazur, 2001; Gok, 2012; Li $\&$ Singh, 2017). The IE methods are those methods designed at least in part to promote conceptual understanding through interactive engagement of students in heads-on and hands-on activities which yield immediate feedback through discussion with peers and/or instructors (Hake, 1998). Peer instruction, tutorials, and simulations activities are some methods of interactive engagement methods. Peer Instruction has been reported to be effective in increasing students' mastery of both conceptual reasoning and quantitative physics problem-solving (Mazur, 1997; Crouch \& Mazur, 
2001; Yadav, 2005; Gok, 2012; Šestáková, 2013; Mbonyiryivuze, Kanamugire, Yadav, \& Ntivuguruzwa, 2018).

Peer Instruction is one of the popular pedagogies that was developed and popularized by Mazur at Harvard University in the 1991. While developing Peer Instruction, Mazur could improve his Harvard undergraduates' conceptual understanding of introductory physics (Mazur, 1997). Peer Instruction is a widely used pedagogy in which lectures are interspersed with short conceptual questions (ConcepTests) designed to reveal common misunderstandings and to actively engage students in lecture courses (Mazur, 1997; Crouch \& Mazur, 2001; Fagen, Crouch, \& Mazur, 2002). Actually, the fundamental goal of implementing peer instruction strategy in class is to exploit student interaction during lectures and focus students' attention on underlying concepts (Mazur, 1997). Besides emphasising physics concepts, this teaching method is also used to achieve good students' performance on physics problem-solving (Yadav, 2005). For the peer instruction, lectures consist of several short presentations on key points. Each presentation is followed by a ConcepTest that is a short conceptual question on the subject being discussed (Mazur, 1997). Actually, the students are first given time to formulate answers and then asked to discuss their answers with each other. Using this teaching method, the students are forced to think through the arguments being developed. Moreover, this provides a way to assess students understanding of the concept for both students and teachers (Mazur, 1997). Peer Instruction has been acclaimed to be an easy-to-use method that fosters active learning in secondary schools, undergraduate, and graduate classrooms across the globe (Schell \& Butler, 2018). Research has confirmed that courses that integrate Peer Instruction produce greater student achievement compared to traditional lecture-based courses. Moreover, Peer Instruction has been reported to produce a host of valuable learning outcomes, including better conceptual understanding, more effective problem-solving skills, increased student engagement, and greater retention of students in science majors (Schell $\&$ Butler, 2018). It was recommended by (Yadav, 2005) that formative assessment should be frequently arranged during instruction in various forms to monitor learning progress. Moreover, he suggested that use of ConceptTest type questions suggested in Peer Instruction manual (Mazur, 1997), checkpoints and questions provided in the Fundamental of Physics Book by Halliday Resinick and Walker (Halliday, Resnick, \& Walker, 1997) can be useful.

\section{Conclusions}

Success in quantitative problem-solving is not a reliable measure of conceptual understanding. Students need to be assisted in developing their physics conceptual understanding allowing them to link physics with the real world and then developing their problem-solving skills. Students with both good physics conceptual understanding and problem-solving skills will be able to relate the important information to what they already know without just memorizing it the way it is presented. Students' preconceptions about the new concepts and their background, teaching methods, and teachers are among factors influencing students' conceptual understanding. This review paper reported about the impact of students' preconceptions on learning and the importance of considering students' preconceptions for effective learning. In fact, effective learning process is considerably hindered by students' preconceptions about the topic. Therefore, teachers need to identify students' prior knowledge before introducing new concepts. This will ease the identification of appropriate teaching strategies helping students to overcome their misconceptions. Even if electricity and magnetism topic is considered as one of the central areas of physics and science curricula at primary, secondary and tertiary levels of education, studies show that there are several concepts in which students develop views that are different from those accepted scientifically. Thus, some studies on students' conceptual understanding of electricity and magnetism have been highlighted in this paper. Furthermore, some proposed possible 
remedies to overcome students' misconceptions have been discussed. Remedies including constructive alternative approaches like problem-based learning strategies, inquiry-based approaches, and Interactive Engagement methods including Peer Instruction are discussed.

\section{Educational Implications and Recommendation}

The research on students' conceptual understanding has some important implications on teaching and learning of physics, physics curriculum reform, etc. So, this paper is important for all physics educators and researchers in science education reforms. Teachers must acknowledge and take into consideration the role of prior knowledge and misconceptions hold by students as they strongly influence their learning process. A teacher can affect the teaching and learning process for a higher degree of conceptual change by understanding students' prior knowledge about a concept. Therefore, teachers are encouraged to assess students' prior knowledge, misconceptions, and areas where students have difficulties before introducing a new physics course. This assessment of students' prior knowledge and misconceptions about a topic before its teaching can help teachers to prepare lessons and strategies helping students to address their previous misconceptions in the subject matter. Teachers have to allow their students to deal with their initial knowledge and help them formulate a qualitative understanding of currently accepted physics concepts or expert views. Students need active participation in constructing their knowledge into a consistent global structure. It is also important to emphasize the identification of students' preliminary knowledge and misconception to teachers and student teachers. Some misconceptions have been reported to emerge from the country's culture, language and teaching strategies (Turgut, Gürbüz, \& Turgut, 2011; Küçüközer \& Kocakülah, 2007). Therefore, there is a need to take into consideration those culture, language, and teaching based misconceptions during teaching and designing activities aiming to overcome these misconceptions. Moreover, teachers have to be warned about the misconceptions caused by the use of language in the curriculum and the teachers' handbook. To help learners to be aware of possible misconceptions and their corrections, the use of conceptual textbook which is a self-explanatory textbook containing misconceptions and their corresponding correct explanations is recommended. Moreover, there is a need for the introduction of the constructivist teaching approach in teachers' training curriculum so that learners are being taught using the same approach. Research found inadequacies among physics teachers that would most likely to be associated with inadequacies in the contents and quality of undergraduate physics teaching (Gunstone, Mulhall, \& McKittrick, 2009). Thus, there is a need for probing university physics academics on ways they understand basic concepts of electricity and magnetism. Teachers training colleges should introduce possible misconceptions and corresponding ways of correction for electricity and magnetism topics and student teachers should be trained on how to clarify those misconceptions and their corresponding corrections. Moreover, microteaching for teacher trainees may be important to develop skills to teach physics concepts together with specific abilities required to do physics (Yadav, 2005). Finally, there is an imperative need for further research on the permanent effects of identified potential instructional strategies improving students' conceptual understanding of electricity and magnetism. The same studies can also be extended for other instructional strategies improving students' conceptual understanding in other physics topics as well as other science subjects.

\section{Acknowledgement}

Financial support provided by the African Centre of Excellence for Innovative Teaching and Learning Mathematics and Science (ACEITLMS) is thankfully acknowledged. 
Students' conceptual understanding of electricity and magnetism and its implications: A review

A. Mbonyiryivuze, L. L. Yadav, \& M. M. Amadalo

\section{References}

Abdullaha, N., \& Limb, B. K. (2012). Parallel circuit conceptual understanding test (PCCUT). 6th International Conference on University Learning and Teaching (InCULT 2012). 90, pp. 431 - 440. Elsevier Ltd.

Afra, N. C., Osta, I., \& Zoubeir, W. (2009). Students' alternative concepts about electricity and the effect of inquiry-based teaching strategies. International Journal of Science and Mathematics Education, 7(1), 103-132.

Alwan, A. A. (2011). Misconception of heat and temperature among physics students. Procedia Social and Behavioral Sciences, 12, 600-614.

Amadalo, M. M., Ocholla, A. A., \& Sakwa, T. W. (2016). Physics practical work and its influence on students' academic achievement. Journal of Education and Practice, 7(28), 129-134.

Arnold, M., \& Millar, R. (1987). Being constructive: An alternative approach to the teaching of introductory ideas in electricity. International Journal of Science Education, 9(5), 553563.

Aydeniz, M. (2010). Measuring the impact of electric circuits Kit book on elementary school children's understanding of simple electric circuits. Electronic Journal of Science Education, 14(1), 1-29.

Cakir, M. (2008). Constructivist approaches to learning in science and their implications for science pedagogy: A literature review. International Journal of Environmental \& Science Education, 3(4), 193-206.

Christensen, W. M., Meltzer, D. E., \& Nguyen, N.-L. (2011). Student understanding of calorimetry in introductory calculus-based physics. American Journal of Physics, 79(11), 1168-1176.

Clement, J. (1982). Students' preconceptions in introductory mechanics. American Journal of Physics, 50(1), 66-71.

Coletta, V. P., \& Philips, J. (2005). Interpretation of FCI scores: Normalized gain, preinstruction scores, and scientific reasoning ability. American Journal of Physics, 73(12), 1172-1182.

Crouch, C., \& Mazur, E. (2001). Peer Instruction: Ten years of experience and results. American Journal of Physics, 69(9), 970-977.

Ding, L., Chabay, R., Sherwood, B., \& Beichner, R. (2006). Evaluating an electricity and magnetism assessment tool: Brief electricity. Physical Review Special Topics - Physics Education Research, 2(1), 010105-1-010105-7.

Driver, R., Asoko, H., Leach, J., Mortimer, E., \& Scott, P. (1994). Constructing scientific knowledge in the classroom. Educational Researcher, 23(1), 5-12.

Dufresne, R. J., \& Gerace, W. J. (2004). Assessing-to-Learn: Formative assessment in Physics instruction. The physics Teacher, 42(7), 428-433.

Elby, A. (1999). Another reason that Physics students learn by rote. American Journal of Physics, 67(7), S52-S57.

Engelhardt, P. V., \& Beichner, R. J. (2004). Students' understanding of direct current resistive electrical circuits. American Journal of Physics, 72(1), 98-115. 
Fagen, A. P., Crouch, C. H., \& Mazur, E. (2002). Peer instruction: Results from a range of classrooms. The Physics Teacher, 40(4), 206-209.

Glauert, E. B. (2009). How young children understand electric circuits: Prediction, explanation, and exploration. International Journal of Science Education, 31(8), 1025-1047.

Gok, T. (2012). The impact of peer instruction on college students' beliefs about physics and conceptual understanding of electricity and magnetism. International Journal of Science and Mathematics Education, 10(2), 417-436.

Goldberg, F. M., \& McDermott, L. C. (1987). An investigation of student understanding of the real image formed by a converging lens or concave mirror. American Journal of Physics, 55(2), 108-119.

Gunstone, R., Mulhall, P., \& McKittrick, B. (2009). Physics teachers' perceptions of the difficulty of teaching electricity. Research in Science Education, 39(4), 515-538.

Hake, R. R. (1998). Interactive-engagement versus traditional methods: A six-thousand-student survey of mechanics test data for introductory physics courses. American Journal of Physics, 66(1), 64-74.

Halliday, D., Resnick, R., \& Walker, J. (1997). Fundamentals of Physics . New York: John Wiley \& Sons.

Halloun, I. A., \& Hestenes, D. (1985). The initial knowledge state of college physics students. American Journal of Physics, 53(11), 1043-1055.

Hestenes, D., Wells, M., \& Swackhamer, G. (1992). Force Concept Inventory. Physics Teacher, 30(3), 141-158.

Hussain, N. H., Latiff, L. A., \& Yahaya, N. (2012). Alternative conception about open and short circuit concepts. Procedia - Social and Behavioral Sciences, 56, 466- 473.

Kanamugire, C., Yadav, L. L., \& Mbonyiryivuze, A. (2019). Tutors' perceptions about science curriculum reforms and challenges for their implementation in Teacher Training Colleges in Rwanda. African Journal of Educational Studies in Mathematics and Sciences, 15(1), 101-116.

Küçüközer, H., \& Kocakülah, S. (2007). Secondary school students' misconceptions about simple electric circuits. Journal of Turkish Science Education, 4(1), 101-115.

Lark, A. (2007). Student misconceptions in Newtonian mechanics. College of Bowling Green State University.

Li, J. (2012). Improving students' understanding of electricity and magnetism. University of Pittsburgh.

Li, J., \& Singh, C. (2017). Developing and validating a conceptual survey to assess introductory physics students' understanding of magnetism. European Journal of Physics, 38(2), 1-28.

Li, J., \& Singh, C. (2017). Investigating and improving introductory physics students' understanding of the electric field and the superposition principle. European Journal of Physics, 38(5), 1-28. 
Students' conceptual understanding of electricity and magnetism and its implications: A review

A. Mbonyiryivuze, L. L. Yadav, \& M. M. Amadalo

Maloney, D. P., O’Kuma, T. L., Hieggelke, C. J., \& Heuvelen, A. V. (2001). Surveying students' conceptual knowledge of electricity and magnetism. American Journal of Physics, 69(7), S12-S23.

Mashood, K. K., \& Singh, V. A. (2012). An inventory on rotational kinematics of a particle: Unravelling misconceptions and pitfalls in reasoning. European Journal of Physics, 33(5), 1301-1312.

Mazur, E. (1997). Peer Instruction-A User's Manual. New Jersey, Upper Saddle River: PrenticeHall.

Mbonyiryivuze, A., Kanamugire, C., Yadav, L. L., \& Ntivuguruzwa, C. (2018). Reforms in science curricula in the last six decades: Special reference to physics. African Journal of Educational Studies in Mathematics and Sciences, 14, 153-165.

McColgan, M. W., Finn, R. A., Broder, D. L., \& Hassel, G. E. (2017). Assessing students' conceptual knowledge of electricity and magnetism. Physical Review Physics Education Research, 13(2), 020121-1-020121-19.

McDermott, L., \& Shaffer, P. (1992). Research as a guide for curriculum development: An example from introductory electricity. Part I: Investigation of student understanding. American Journal of Physics, 60, 994-1003.

Mioković, Ž., Ganzberger, S., \& Radolić, V. (2012). Asssessment of the University of Osijek engineering students' conceptual understanding of electricity and magnetism. Tehnički vjesnik, 19(3), 563-572.

NRC. (1997). Misconceptions as barriers to understanding science. In C. o. Education, Science teaching reconsidered: A handbook. Washington, D.C: National Academy Press.

Moodley, K., \& Gaigher, E. (2019). Teaching electric circuits: Teachers' ideas and understanding of misconceptions. Research in Science Education, 49(1), 73-89.

Muise, J. M. (2015). Using Peer Instruction to promote conceptual understanding in high school physics classes. Montana: Montana State University.

Mulhall, P., Brian, M., \& Gunstone, R. (2001). A perspective on the resolution of confusions in the teaching of electricity. Research in Science Education, 31, 575-587.

Muthiraparampil, S. T. (2012). Misconception in electrostatics among learners at university entry point: A South African case study point: A South African, Dissertation. Walter Sisulu University.

NRC. (1997). Misconceptions as barriers to understanding science. In C. o. Education, Science teaching reconsidered: A handbook. Washington, D.C: National Academy Press.

Philippi, K. H. (2010). An examination of student understanding of the use of models in science and conceptual understanding of electricity and magnetism: PhD Thesis. University of New Orleans.

Pollock, S. J. (2009). A longitudinal study of student conceptual understanding of electricity and magnetism. Physical Review Special Topics - Physics Education Research, 5(2), 0201101-020110-8.

Posner, G. J., Strike, K. A., Hewson, P. W., \& Gertzog, W. A. (1982). Accommodation of a scientific conception: Toward a theory of conceptual change. Science Education, 66(2), 211-227. 
Rathore, R. (2016). Surveying students' misconceptions and understanding in nuclear physics. Journal of Applied Physics, 8(1), 7-10.

Schell, J., \& Butler, A. C. (2018). Insights from the science of learning can inform evidence-based implementation of peer instruction. Frontiers in Education, 3(33), 1-13.

Šestáková, J. (2013). Peer Instruction and students' understanding of physics. (pp. 97-99). WDS'13 Proceedings of Contributed Papers.

Shaffer, P. S., \& McDermott, L. C. (1992). Research as a guide for curriculum development: An example from introductory electricity. Part II: Design of instructional strategies. American Journal of Physics, 60(11), 1003-1013.

Sukariasih, L. (2016). The use of cognitive conflict strategy to reduce student misconceptions on the subject matter of rectelinear motion. International Journal of Education and Research, 4(6), 483-492.

Turgut, Ü., Gürbüz, F., \& Turgut, G. (2011). An investigation $10^{\text {th }}$-grade students' misconceptions about electric current. Procedia Social and Behavioral Sciences, 15, 1965-1971.

Uwizeyimana, D., Yadav, L. L., Musengimana, T., \& Uwamahoro, J. (2018). The impact of teaching approaches on effective physics learning: an investigation conducted in five Secondary Schools in Rusizi District, Rwanda. Rwandan Journal of Education, 4(2), 2-14.

Van der Merwe, O. R., \& Gaigher, E. ( 2011). Exploring teachers' awareness of misconceptions about series and parallel circuits. ISTE International Conference on Mathematics, Science and Technology Education (pp. 181-190). Kruger Park: ISTE.

Villarino, G. N. (2015). Students' alternative conceptions and patterns of understanding on electric circuits. International Journal of Science and Research, 7(3), 482-488.

Von Korff, J., Archibeque, B., Gomez, K. A., Heckendorf, T., McKagan, S. B., C. Sayre, E., Sorell, L. (2016). Secondary analysis of teaching methods in introductory physics: A 50 k-student study. American Journal of Physics, 84(12), 969-974.

Wallace, J., \& Louden, W. (1998). Curriculum change in science: Riding the waves of reforms. In the International book of science education (pp. 471-485). London: Kluwer.

Wieman, C., \& Perkins, K. (2005). Transforming physics education. Physics Today, 58(11), 3641.

Yadav, L. L. (2005). Part 3: Physics teaching methods. In Education Module 11: Mathematics and physics teaching methods. Kigali: Kigali Institute of Education 